\title{
Evaluating Surface Material Loss for Gravel Road
}

\author{
Mengistu Mena Kuleno \\ Lecturer, Department of Civil Engineering, Wolaita Sodo University, Ethiopia \\ Yohannis Endrias Yacob \\ Project Manager, South Roads Authority, Wolaita Sodo District, Ethiopia
}

\begin{abstract}
Gravel roads require a continuous maintenance and regraveling cycle to maintain the required surface quality and the desired level of service. Surface material loss is a way of deterioration of unpaved road by which the reduction of thickness of gravel wearing course by various factors through time. To keep it in mind the responsible body or roads authority should predict the gravel loss in order to account for maintenance or rehabilitation requirement after a given period. This should be based up on regraveling frequency from predicted gravel loss during construction or after the first maintenance. Here main factors included for study are ADT, mean monthly precipitation of locations, plasticity index of surfacing material and absolute value of gradient of the road as independent variables and gravel loss as dependent variable. The road segments selected are Sodo-Gesuba road(29km), Humbo-Menuka(13km) and Sodo zuriya-Gulgula $(11 \mathrm{~km})$ road segments. The monthly rainfall data from SNNPR meteorological agency was used as secondary data and all other data was collected from field survey. The data collected for modeling are based up on the basic scientific methods and collected data was analyzed by statistical software IBM SPSS statistics 20 and Microsoft Excel 2019 in order to develop a model. The developed model indicates that gradient of the road is critical factor hence its unit change accelerates loss of gravel by 4.7316, a unit change in ADT lead to 0.1225 change in gravel loss, a unit change in mean monthly precipitation of locations lead to 0.1460 change in gravel loss and a unit change in plasticity index of surfacing material lead to -1.3473 change in gravel loss. From regression output $\mathrm{R} 2$ also called coefficient of determination which is the proportion of variance in the dependent variable that can be explained by the independent variables, and is equal to 0.985 for model which means gravel loss contributing factors here in this study explain $98.5 \%$ of variability of gravel loss and that statistical package strongly reinforced the correlation.
\end{abstract}

Keywords: Gravel loss, Regraveling, gravel resurfacing, absolute gradient, multiple linear regression and modeling

DOI: $10.7176 / \mathrm{CMR} / 11-6-02$

Publication date: August 31st 2019

\section{INTRODUCTION}

Transportation plays vital role in every nation across the world. The mobility of these nations is mainly depending up on transportation facility available. In Ethiopia mode of transportation most widely used is Road transportation. Under the study of road transportation there are various influencing factors affecting the safety and comfort of users. In Ethiopia Economic Growth highly depends up on agricultural sector and these agricultural products are transported by using road infrastructure as freight transport from one place to another in addition to these there are also passengers traveling from one place to another. Hence the road sector development among other basic rural infrastructure is very essential for economic growth. Roads are classified in to paved, unpaved and earth roads based up on the way of construction and surfacing material used. Paved roads are roads with Asphalt concrete and Portland cement concrete pavements. Unpaved roads are roads with surfacing material of gravel or other sub base materials and earth roads are roads with surfacing of locally available earth or soil type material. Unpaved roads deteriorate rapidly than a paved road because of it is susceptible to various factors as its construction cost is minimum. Therefore, unpaved roads should have given priority maintenance as its construction cost is minimum and maintenance cost is high.

Gravel road is defined as a road surfaced with processed, generally crushed and screened, imported granular aggregate.Gravel roads are generally unpaved roads that may give service to the traveling public and are usually have given lowest attention than to paved roads.

As stated in ERA (2013) under Federal road network improvement about $60 \%$ of roads are gravel roads and is about $14,675 \mathrm{KM}$ and the remaining $40 \%$ which is $9,875 \mathrm{KM}$ are paved roads and in Regional road network development there is about $31,550 \mathrm{KM}$ gravel road in Ethiopia. From this point there is about $82.4 \%$ of gravel road in Ethiopia and the remaining 17.6\% road is paved. Gravel roads in general give access for community. Moving from place to place for social, political and economic experience and market exchange should improve the development of the whole country. There for this study mainly concerns for Gravel roads necessary for access.

For the limited volume of traffic, paving and maintaining a road is not economically feasible. Economic constraints for gravel roads are the only option that can be provided (Skorseth \& Selim, 2000). The causes of 
deterioration combined with the extent of the failures must be considered together when selecting the most appropriate method of maintenance or rehabilitation. Therefore, the cause and extent of gravel road should be primarily identified and to be recommended for remedial measures.

Gravel loss is defined as the change in average gravel thickness over a period of time. Gravel loss was evaluated for the interval between gravel resurfacing, which was initiated a new construction cycle, or from the time of the first observation until a regraveling occurred. Three major factors identified as affecting gravel loss were climatic, traffic and the influence of blading. Material properties and road geometry and road cross section influence the gravel loss generated by each of these factors (Skorseth \& Selim, 2000).

\subsection{General Objective}

The main objective of this study is to evaluate the performance of Gravel Roads prior to surface material loss in order to account for maintenance and rehabilitation.

\subsection{Specific Objectives}

1. To study the causes of Gravel losses

2. To predict level of deterioration or surface material loss for gravel roads

3. To develop a model used to predict gravel loss

4. To forward information on gravel loss in order to suggest effective management system for gravel roads

\subsection{Statement of The Problem}

Gravel loss is problem arising when there is loss of surface materials from gravel roads and also results change in thickness of the unpaved gravel roads. From various problems the study of the loss of gravel is very crucial because of it results in: Accelerated accident in road users, High vehicle operating cost (VOC), Discomfort and affects safety of users, reduce level of service (LOS), Makes movements more problematic, Increases the rate of maintenance cost and Reduces the life of the road.

The study included different parameters to depict the gravel loss models. The model developed most probably used to help road management bodies to manage the road infrastructure properly by assessing climate, surfacing material property, road geometry and traffic using the road.

\subsection{Scope of The Study}

This research study is carried out on Sodo-Gesuba, Humbo-Menuka and Sodo zuriya-Gulgula roadway segments. This research work has been done on the road networks of SNNPR, Wolaita zone, Ethiopia. Length of SodoGesuba road segment is $29 \mathrm{~km}$, length of Humbo-Menuka road segment is $13 \mathrm{~km}$ and length of Sodo zuriya-Gulgula road segment is $11 \mathrm{~km}$ and factors assessed for study were ADT, PI of surfacing material, Gradient of the road section and Rainfall data for the location.

\section{REVIEW OF THE LITERATURE}

Gravel road may not be appropriate where the quality of surface material is poor, rainfall intensity is very high and traffic volume is high, longitudinal gradient is greater than $6 \%$ and adequate maintenance may not be provided. Gravel roads have low construction cost but have high maintenance cost.

The major technical challenges for unpaved roads are to provide surfacing with materials that provide the desired and necessary level of service and to provide effective maintenance management. Vehicle operating costs (VOCs) are high on unpaved gravel roads with high roughness and restricted access. VOCs include vehicle repairs, maintenance, fuel consumption, tire replacement and others. The consequence is that transport operators tend to avoid roads with high roughness and other defects forcing people to walk long distances to reach. The dust is often a main problem on unpaved roads. It is caused by the action of traffic and wind (ERA, 2011).

An economic evaluation of various maintenance strategies for the management of unpaved roads is dependent on a reliable determination of level and type of deterioration and the value of maintenance operations. The rate at which maintenance and gravel resurfacing should be applied are dependent on the economic variation between the costs of the maintenance and the benefits to be gained from increasing level of service. Empirical prediction deterioration models therefore, need to determine the effective rates of deterioration as a function of traffic, road geometry, material properties, climate and the surfacing maintenance type used (Paterson, 1991).

According to Paige-Green (1990) Typical defects which may affect unpaved roads are dustiness, potholes, stoniness, corrugations, ruts, cracks, ravelling, erosion, slipperiness, impassability and loss of surfacing or wearing course. Most of these have a direct effect on the road roughness and safety.

As stated in Henning, et al. (2008) Loss of surface material is particularly vital for gravel roads, where the loss or replacement of lost surface material that shall costs a lot.

Rates of gravel loss are influenced by various factors depending on road geometry, material quality, traffic numbers and type, climatic conditions, construction standards and maintenance practices. 
The traffic volume and rainfall, combined with lack of strength and cohesion in pavement materials, leads to a loss of pavement materials. Surface material is lost by the actions of scouring, 'kick off', dust, attrition, stones breaking down through the passage of heavy vehicles and on weak subgrades traffic ingress pavement materials into the subgrade.

Giummarra, et al. (2007) stated that, gravel loss mainly focus on functional contributing factors as time period in hundreds of days (days/100), average daily vehicular traffic in both directions, in vehicle/day, mean monthly precipitation, in $\mathrm{mm} / \mathrm{month}$ and surface material property which is plasticity factor and model

\section{METHODOLOGY OF THE RESEARCH}

\subsection{Study Area}

This research work has been done on the road networks of SNNPR, Wolaita zone, Ethiopia. The Study area is arbitrarily selected based on traffic flow characteristics, geometric appearances, climatic locations of the area and also surface materials used for the road. Such road segments selected for the study are Sodo-Gesuba(29km), HumboMenuka(13km) and Sodo Zuriya-Gulgula $(11 \mathrm{~km})$ Roads.

\subsection{Methods for obtaining Traffic data}

Information on traffic volume, composition and loading are important factors in the determination of the appropriate standard of a road. According to ERA (1998) Traffic counting is the process of recording the frequency of traffic at a specific location on a specific road segment at a specified time. The census should therefore, be taken at locations which are representative of the traffic characteristics of a particular area or type of road. Vehicles to be counted shall be as classified in Table below.

Table1: Vehicle composition

\begin{tabular}{|c|c|}
\hline Classification & Description \\
\hline \multicolumn{2}{|r|}{ A. Passenger Vehicles } \\
\hline Car & Cars and Taxis \\
\hline L/Rover & Land Rovers, Jeeps, Station Wagons, Land Cruisers etc. \\
\hline $\mathrm{S} / \mathrm{Bus}$ & Small Buses with up to 24-passenger seats \\
\hline L/Bus & Large Buses with over 24-passenger seats \\
\hline \multicolumn{2}{|r|}{ B. Freight Trucks } \\
\hline S/truck & Small and light trucks less than 3 tons load \\
\hline $\mathrm{M} /$ Truck & Medium sized trucks between 3- and 7-tons load \\
\hline $\mathrm{H} /$ Truck & Heavy trucks and tankers between 7- and 12-tons load \\
\hline Truck-Trailer & Truck trailers and tanker trailers above 12 tons load \\
\hline
\end{tabular}

The study was estimated ADT of each road sections. ADT is defined as the total traffic volume during a given time period in whole days greater than one day and less than one year divided by the number of days in that period (ERA, 2013).

The type of traffic in each day was recorded. The traffic for sample roads is counted manually by enumerators for two direction of traffic movement for 12 hours and shall be projected for 24 hours by counting 2 additional days i.e., Friday and Saturday night time traffic that has been counted in order to get adjusting factors for day time traffic. From 12 A.M to 1 P.M local time (LT) day time traffic count was taken for seven (7) days and for Friday and Saturday night time traffic count from 1P.M to 12 A.M is taken and then it may give Adjusting factor for day time and multiply day time traffic by adjusting factor in order to get total ADT (average daily traffic) for each of selected Road segments

Table-2: ADT estimated for heavy and light vehicles

\begin{tabular}{|l|l|l|l|l|l|l|}
\hline \multirow{2}{*}{ Road segments } & \multicolumn{2}{|l|}{ Sodo-Gesuba road } & \multicolumn{2}{l|}{ Humbo-Menuka road } & \multicolumn{2}{l|}{ Sodo zuriya-Gulgula road } \\
\hline Days & $\begin{array}{l}\text { Light } \\
\text { vehicles }\end{array}$ & $\begin{array}{l}\text { Heavy } \\
\text { vehicles }\end{array}$ & Light vehicles & $\begin{array}{l}\text { Heavy } \\
\text { vehicles }\end{array}$ & Light vehicles & $\begin{array}{l}\text { Heavy } \\
\text { vehicles }\end{array}$ \\
\hline Monday & 50 & 150 & 32 & 111 & 22 & 91 \\
\hline Tuesday & 35 & 114 & 36 & 92 & 25 & 70 \\
\hline Wednesday & 29 & 146 & 23 & 87 & 18 & 71 \\
\hline Thursday & 41 & 142 & 25 & 89 & 29 & 96 \\
\hline Friday & 36 & 123 & 20 & 101 & 15 & 89 \\
\hline Saturday & 39 & 143 & 29 & 106 & 21 & 108 \\
\hline Sunday & 33 & 107 & 24 & 65 & 17 & 60 \\
\hline Average ADT & $41 \mathrm{veh} /$ day & $145 \mathrm{veh} /$ day & $30 \mathrm{veh} /$ day & $102 \mathrm{veh} /$ day & $23 \mathrm{veh} /$ day & $92 \mathrm{veh} /$ day \\
\hline Total ADT & 186 & 132 & & 115 & \\
\hline
\end{tabular}




\subsection{The gravel loss Data Collection}

Gravel loss or surface material loss has been obtained by selecting major damaged or deteriorated sections of different locations of the road. The researcher collected gravel loss data of three road segments later after six months of maintenance operation of each selected segments hence surfacing material loss depends up on days after operation of the first maintenance or after construction period of the road. The data collection is carried out by using three metal pegs at one section and by tensioning a string and using water level in order to take account for normal cross fall or crown slope of the section and measure the reduced thickness of surface material at a point by meter stick.

The number of sections taken for each road segments is equal. The researcher decided to study 46 sections in each segment of the road. Hence the sections used for the 3 sample roads are 138 and in each section there are 8 data records such as at the $0.5 \mathrm{~m}$ from edge of the road, $1 \mathrm{~m}$ from edge of the road, $2 \mathrm{~m}$ from edge of the road, at the center of the road, $4 \mathrm{~m}$ from the edge of the road, $5 \mathrm{~m}$ from the edge of the road, $6 \mathrm{~m}$ from the edge of the road and finally $0.5 \mathrm{~m}$ from another or opposite edge of the road. All records are taken from one side to another opposite side. i.e. from left side to right side for all road segments and sections of the road. After record of these data, for convenience all these data in one section is going to be averaged in order to analyze one accurate data for one section.

As per ERA design manual 2013 for all road segments normal cross fall taken is $4 \%$ which is determined by stretch of string through pegs and road width in this case for all road segments the road width is $7 \mathrm{~m}$ and in addition water level is used in order to check the precision.

\subsection{Rainfall Data}

Rainfall is the amount of water falling in a place during a particular period. It is referred as the amount of precipitation falling over a given area in a given period of time. It is stated in terms of the depth of water that has fallen in to a rain gauge measured in $\mathrm{mm}$. The rain fall data is gathered from secondary source which is got from Southern Nations Nationalities and Peoples Region Meteorological Agency office, Hawassa. The data is grouped in to months of the year and study period taken starting from 2013G.C to 2017G.C for 5 years. Then 5-year data should be averaged in order to get mean monthly precipitation of the area. i.e. for Sodo-Gesuba road segment the mean monthly precipitation of Sodo area has been calculated and is about $111.7 \mathrm{~mm} / \mathrm{month}$, For Humbo-Menuka road segment it is about $94.0 \mathrm{~mm} / \mathrm{month}$ and For Sodo Zuriya-Gulgula road it is about $99.4 \mathrm{~mm} / \mathrm{month}$.

\subsection{Surface Material Properties}

The data concerning surface material was obtained from laboratory test to determine the plasticity index (PI) which plays a major role. The plastic limit of a soil is the lowest water content determined. The plasticity Index of a soil is the range in water content expressed as percentage of the mass of the oven-dried soil, with in which the soil is in plastic state (AASHTO, 2001). Surfacing or wearing course of gravel roads are taken from respective local quarry sites which is available in near distance from the road. The road segments selected for study have different quarry sites and have also variable material property. In this case Atterberg limit test such as Liquid limit, Plastic limit and Plasticity index is carried out for materials from their respective segments. such Sodo-Gesuba road, Humbo-Menuka road and Sodo Zuriya-Gulgula road.

Table-3: Atterberg limit test result for surfacing material (AASHTO -(T89/T90))

\begin{tabular}{|l|l|l|l|}
\hline Locations & Sodo -Gesuba & Humbo-Menuka & Sodo Zuria-Gulgula \\
\hline Liquid Limit (\%) & 28 & 39 & 41 \\
\hline Plastic Limit (\%) & 16 & 25 & 28 \\
\hline Plasticity Index (\%) & 12 & 14 & 13 \\
\hline
\end{tabular}

\subsection{Gradient of the roads}

Gradient is the elevation difference between two points divided by horizontal distance between these two points multiplied by 100 in order to express it in percentage \%. The method used to find a gradient is by fixing a bench mark or control point by using GPS Essentials for a given point and using a Leveling instrument take a reading for two reference points from Staffa and by using Height of Instrument method the elevation of a point on the section is determined. Then the elevation difference between two points divided by horizontal distance between these two points multiplied by 100 gives gradient of the section in percentage $\%$. In this way the study segments of the road should be separated in a section. Each segment of the road has 46 sections hence totally there are about 138 sections used for the study and each section have their own respective gradient. Absolute value of gradient is used for the study hence the sign of the grade indicates the direction of the road as upward or downward section from the datum.

\subsection{Method of Data Analysis}

For analysis purpose all the collected data is used by first rearranging and organizing each and every primary and secondary data by using Microsoft excel 2019. Multiple linear regression models and Correlation between variables 
had been done by IBM SPSS statistics 20 and Microsoft excel 2019 data analysis for Surface material loss.

\section{RESULTS AND DISCUSSIONS}

The assumption in the multiple linear regression equation is that there is a linear relationship exists between all the independent variables with dependent variable. In this case for model 1 dependent or response variable is gravel loss and independent or predictor variables are Average daily traffic using the road, Mean monthly rainfall in the area, Gradient in \% of the road section \& Plasticity index of surfacing material for Gravel roads. Correlation is the relationship between two variables. The regression output of surface material loss and contributing factors for model is as follows:

Table-4: Regression statistic result summary for model

\begin{tabular}{lr|lr}
\hline \multicolumn{2}{l|}{ Regression Statistics } & \multicolumn{2}{l}{ Coefficients } \\
\hline Multiple R & 0.992 & Intercept & 0.0000 \\
R Square & 0.985 & Pr & 0.1460 \\
Adjusted R Square & 0.974 & PI & -1.3473 \\
Standard Error & 4.214 & ADT & 0.1225 \\
Observations & 105 & Gr & 4.7316 \\
\hline
\end{tabular}

The models developed from this summary is:

\section{$G L=D *[0.1460 * \operatorname{Pr}-1.3473 * \mathrm{PI}+0.1225 * A D T+4.7316 * \mathrm{Gr}]$}

Where

$\mathrm{GL}=$ is Gravel loss in $\mathrm{mm} / 6$ months

$\mathrm{D}=$ is the time period considered in hundred days i.e., days/100 (is the time interval in days or the observation days which is only used to reduce the larger coefficient values in the model) which is 1.8 for this study.

$\mathrm{Pr}=$ is Mean monthly precipitation of location in $\mathrm{mm} / \mathrm{month}$

$\mathrm{PI}=$ is Plasticity Index of surfacing materials

$\mathrm{ADT}=$ is Average daily traffic in vehicles/day

$\mathrm{Gr}=$ is Absolute value of Gradient of the road section in \%.

Based on the above models' different charts are drawn by using Microsoft Excel 2019 as shown: The validity of the model is checked by data that has not been used for model development from all road segments. Approximately one fourth or $25 \%$ of total actual data is used for validity test.

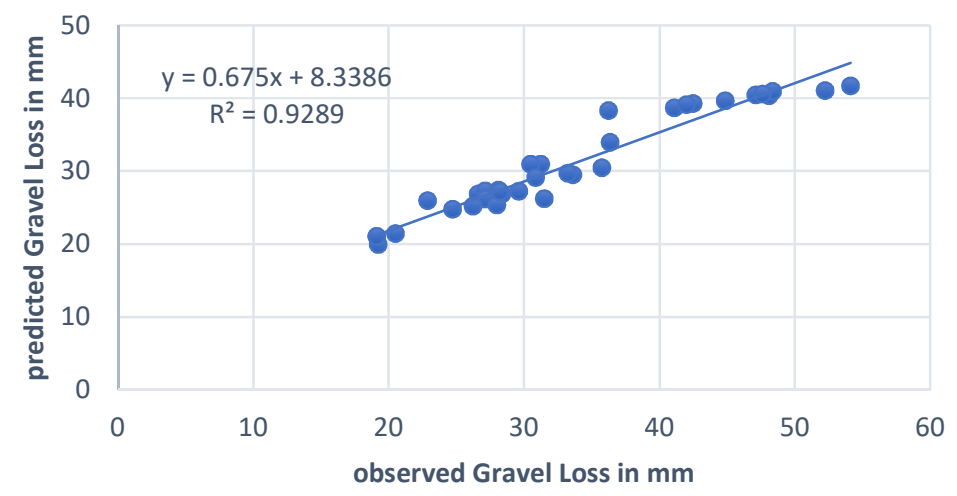

Figure-1: comparing of observed and predicted gravel loss

As shown in figure above model was validated by considering observed or actual gravel loss from site survey for all road segments and predicted gravel loss which was taken by output from the model developed. That means in this case about $25 \%$ of all road traffic in this case ADT, surfacing material property i.e. plasticity index, absolute value of gradient and mean monthly precipitation data was used in the model developed and then actual gravel loss from site survey and predicted gravel loss should be graphed in order to check the validity. Here the scatter plot shows that actual and predicted gravel loss are closer to each other as shown by an imaginary line.

\subsection{Discussion by developing Graphs}

The Surface material or Gravel loss on the study area were correlated with contributing factors by different graphs. For model the graphs were developed by the various ADT, Plasticity Index of surfacing materials, Mean monthly precipitation and Absolute Gradient. The following graphs were developed to explain Predicted Surface material or Gravel loss.

By taking the minimum and maximum values of variables from different point of view and put in ascending order by fixed variation of difference, the model is analyzed in different ways of graph development. In this case 
for model taking Gradient of the road as constant and by varying ADT, PI and Mean monthly precipitation, the predicted gravel loss is as shown below for one graph and by increasing gradient of the road section gradually another different graphs should be developed briefly and it was shown respectively as follows.

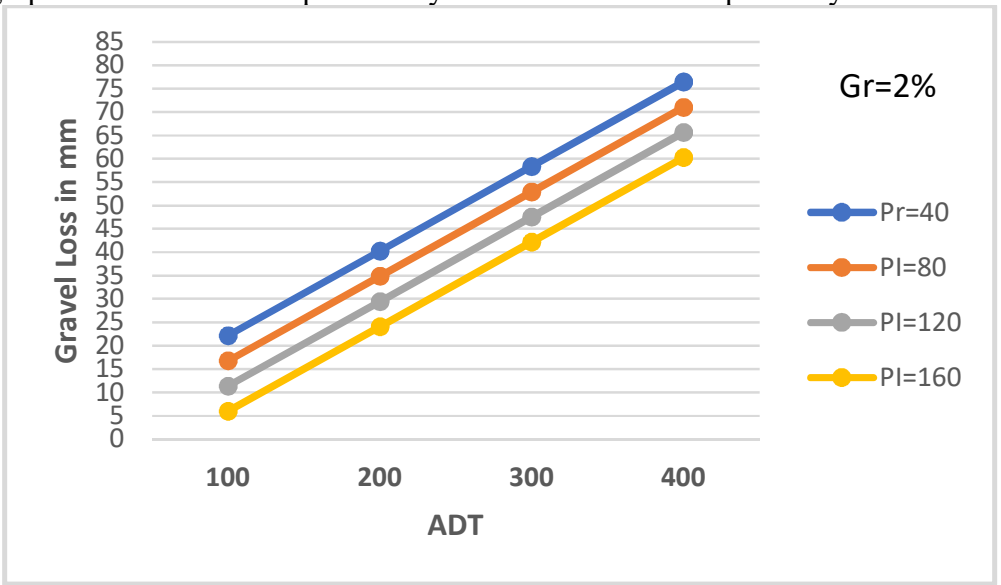

Figure-2: Predicted Gravel loss for 2\% of Gradient

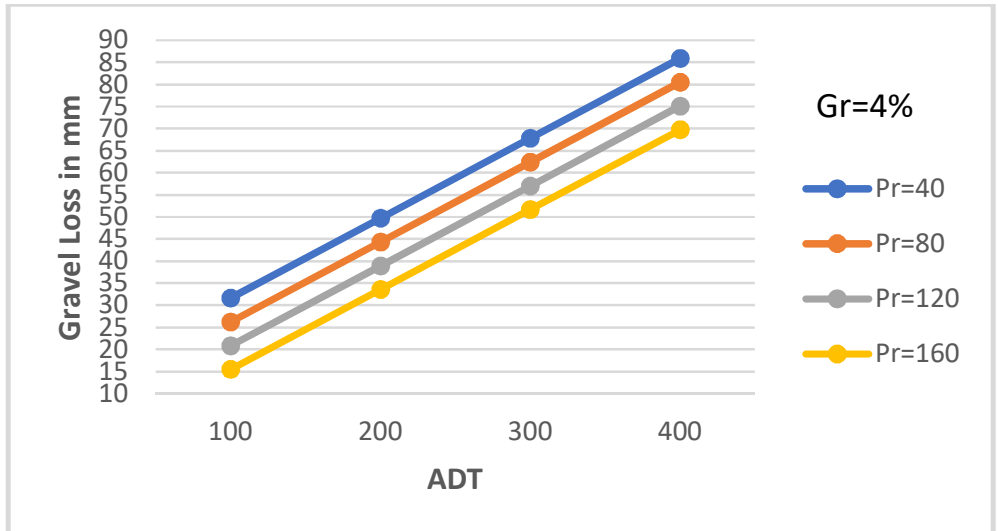

Figure-3: Predicted Gravel loss for $4 \%$ of Gradient

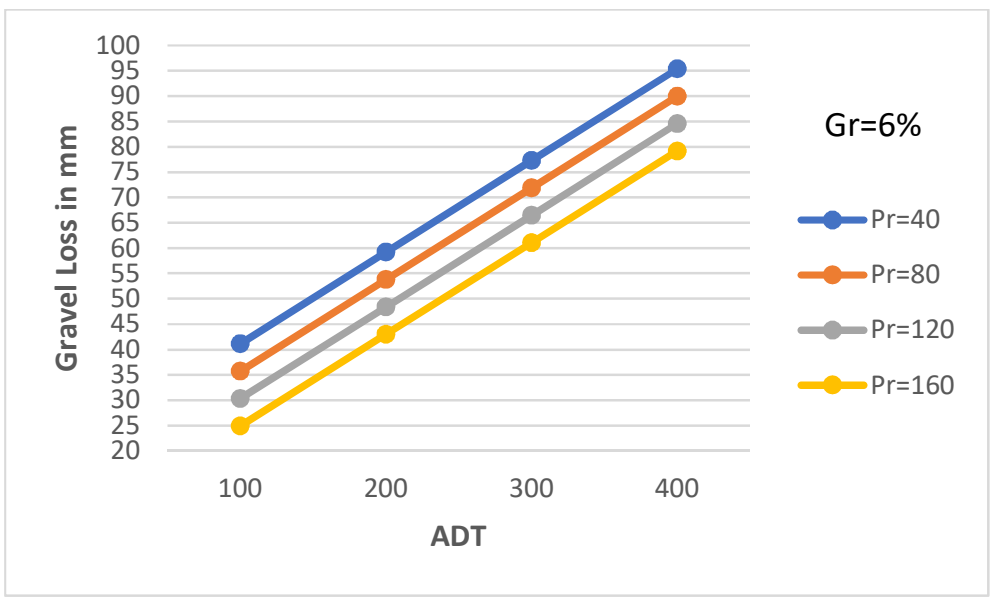

Figure-4: Predicted Gravel loss for $6 \%$ of Gradient 


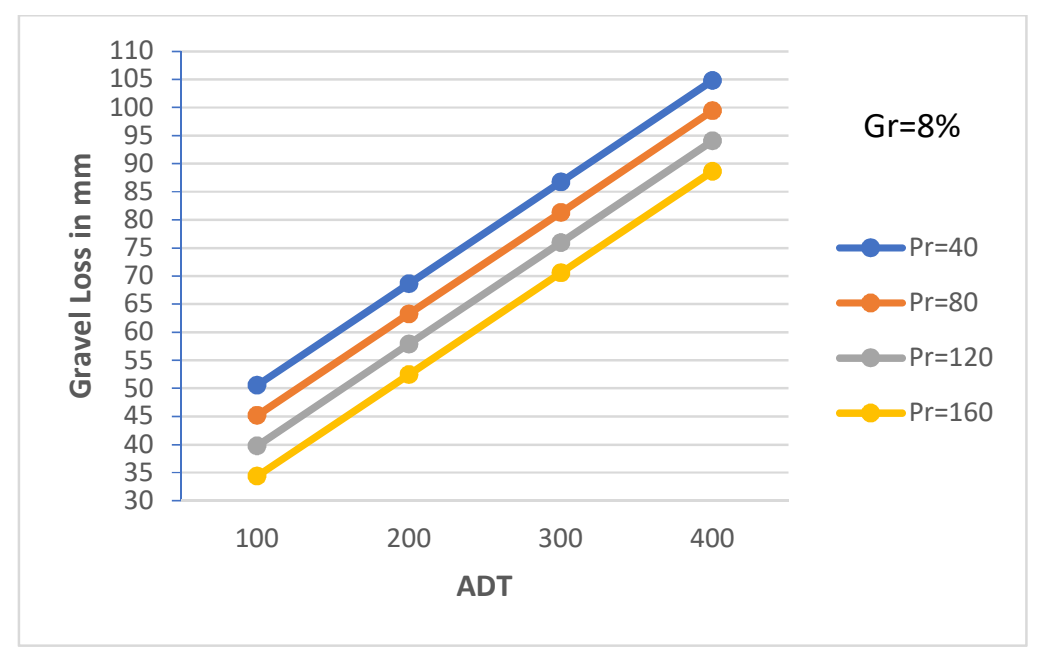

Figure-5: Predicted Gravel loss for $8 \%$ of Gradient

From the above figures it shows that as increase in ADT of vehicles, Plasticity index of surfacing materials and mean monthly precipitation by fixing gradient of the road as constant, there is visible increment of surface material loss and as gradient of the road increases from one point to another there should also be significantly increment in surface material loss as precipitation, PI and ADT goes the same pattern of increment. Here for example by taking gradient of the road section for the first graph as $2 \%$, ADT is $200 \mathrm{veh} / \mathrm{day}$, PI is $4 \%$ and mean monthly precipitation for the location is $80 \mathrm{~mm} / \mathrm{month}$ gravel loss from the graph shows that it is about $40.25 \mathrm{~mm}$ and as for example for the last graph taking gradient of the road section as $8 \%$, ADT is $200 \mathrm{veh} / \mathrm{day}$, PI is $4 \%$ and mean monthly precipitation for the location is $80 \mathrm{~mm} / \mathrm{month}$ gravel loss from the graph shows that it is about $68.64 \mathrm{~mm}$. In the same manner there is influential impact of ADT, PI and mean monthly precipitation with in the same graph as gradient becomes constant.

\section{SUMMARY AND CONCLUSIONS}

Gravel loss predicting model used in this study consider factors such as Average daily traffic, plasticity index of surfacing material, mean monthly precipitation of locations and absolute value of gradient of the road. plasticity index of surfacing material is negatively correlated with gravel loss from correlation result. ADT, mean monthly precipitation of locations and absolute value of gradient of the roads are positively correlated to gravel loss. From the model developed gradient of the road is critical factor hence its unit change accelerates loss of gravel by 4.7316 , a unit change in ADT lead to 0.1225 change in gravel loss, a unit change in mean monthly precipitation of locations lead to 0.1460 change in gravel loss and a unit change in plasticity index of surfacing material lead to -1.3473 change in gravel loss. From regression statistics of IBM SPSS Statistics $20 \mathrm{R}^{\wedge} 2$ also called coefficient of determination which is the proportion of variance in the dependent variable that can be explained by the independent variables, and is equal to 0.984 for model which means gravel loss contributing factors here in this study explain $98.4 \%$ of variability of gravel loss.

From different discussion graphs it shows that as increase in ADT of vehicles, Plasticity index of surfacing materials and mean monthly precipitation by fixing gradient of the road as constant, there is visible increment of surface material loss and as gradient of the road increases from one point to another there should also be significantly increment in surface material loss as precipitation, PI and ADT goes the same pattern of increment. Here for example by taking gradient of the road section for the first graph as $2 \%$, ADT is 200 veh/day, PI is $4 \%$ and mean monthly precipitation for the location is $80 \mathrm{~mm} / \mathrm{month}$ gravel loss from the graph shows that it is about $40.25 \mathrm{~mm}$ and as for example for the last graph taking gradient of the road section as $8 \%$, ADT is $200 \mathrm{veh} /$ day, PI is $4 \%$ and mean monthly precipitation for the location is $80 \mathrm{~mm} / \mathrm{month}$ gravel loss from the graph shows that it is about $68.64 \mathrm{~mm}$. In the same manner there is influential impact of ADT, PI and mean monthly precipitation with in the same graph as gradient becomes constant.

\section{RECCOMENDATIONS}

- Letting mean monthly precipitation under consideration, factors which have a critical effect on gravel loss were gradient of the road section, PI of surfacing materials and ADT for heavy vehicles. To reduce gravel loss by $43.42 \%$, it is recommended to limit maximum longitudinal gradient of $8 \%$, PI of surfacing material should be less than $16 \%$ and ADT should not exceed 200veh/day in order to decrease gravel resurfacing frequency rate. Otherwise the gravel road should be upgraded. 
- In Ethiopia unpaved road management system is very poor due to lack of surface material loss prediction models and other unconsidered but important factors that may take a largest share and play a great role. Therefore, rural roads authority should give prior duly responsibility for gravel loss prediction models and should allocate finance and resource budget required for maintenance. These should help one to determine residual life of gravel roads and gravel resurfacing frequency.

- When concerned body is constructing a gravel road at a construction stage there should be given high consideration for design and supervision requirements to account for factors including ADT of heavy vehicles using the road, maximum permissible gradient of the road section and mean monthly precipitation of locations in order to predict loss of materials in a specified period.

- In order to account budget allocation for maintenance and rehabilitation there must be scientific valuation of cost and benefit analysis for construction projects as per this case rural gravel access road or unpaved road is sharing a largest economic benefit for Ethiopia. Therefore, there should be case wise information on design, construction and maintenance preliminaries used for gravel roads.

\section{REFERANCES}

ERA, 1998. Guidelines For the Design of Gravel Surfaced Roads, Addis Ababa: Ethiopian Roads Authority.

ERA, 2011. Design Manual For Low Volume Roads, Part A, Adis Ababa: Ethiopian Roads Authority.

ERA, 2013. Assesment of 15 years performance of Road sector development program, Addis Ababa: Ethiopian Roads Authority.

Giummarra, J. G., Martin , T., Hoque, Z. \& Roper, R., 2007. Establishing deterioration models for local roads in Australia. Transportation Research Record, 1989-2(1), pp. 270-276.

Henning, T. F. P., Giummarra, G. J. \& Roux, D. C., 2008. The Development of Gravel Deterioration Models for Adoption in a New Zealand Gravel Road Management System, New Zealand: Land Transport New Zealand Research Report.

Paige-Green, P., 1990. TRH 20: The Structural Design, Construction and Maintenance of Unpaved Roads, Pretoria: Division Road Trans Tecknol.

Paterson, W., 1991. Deterioration and Maintenance of unpaved roads:models of roughness and material loss. Transportation Research Record, Volume 1291, pp. 143-156.

Skorseth, K. \& Selim, A. A., 2000. Gravel Roads Maintenance and Design Manual, U.S: U.S Department of Transportation Federal Highway Adminstration. 